HELMINTHOLOGIA, 54, 3: 189 - 198, 2017

\title{
Genetic survey of alveolar and cystic echinococcoses in Romania: first molecular evidence of Echinococcus multilocularis in humans in the country
}

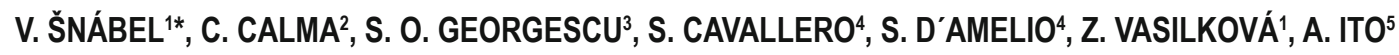

1Institute of Parasitology, Slovak Academy of Sciences, Košice, Hlinkova 3, 04001 Košice, Slovakia, E-mail: *snabel@saske.sk, vasilko@saske.sk; '2Victor Babes University of Medicine and Pharmacy, Department of Physiology and Immunology, 300041 Timisoara, Romania, E-mail: crenguta.calma@gmail.com; ${ }^{3}$ Grigore T. Popa University of Medicine and Pharmacy, Department of Surgery, lași, Romania, E-mail: georgescu_st@yahoo.com; “Department of Public Health and Infectious Diseases, Section of Parasitology, Sapienza University of Rome, Rome, Italy, E-mail: serena.cavallero@uniroma1.it; stefano.damelio@uniroma1.it; ${ }^{5}$ Department of Parasitology, Asahikawa Medical University, Asahikawa 078-8510, Japan, E-mail: akiraito@asahikawa-med.ac.jp

\section{Article info}

Received April 6, 2017 Accepted June 15, 2017

\begin{abstract}
Summary
Cystic echinococcosis (CE) and alveolar echinococcosis (AE) are considered as one of the most important zoonotic diseases in Romania, where they are subject to mandatory reporting. To obtain more knowledge about the genetic diversity of Echinococcus causative agents of these diseases, 11 isolates from humans and ungulate intermediate hosts from the two regions of Romania were genotyped using mitochondrial markers. In clinical samples of five patients from north-eastern Romania (lasi, Botosani, Vaslui counties), Echinococcus multilocularis was identified as causal agent by cox1 sequence analysis. To the best of our knowledge this finding presents the first molecular evidence of $E$. multilocularis in humans from Romania. Only two cases of AE in patients were previously documented in the country by serological methods. In our four patients the most widespread European variant $\mathrm{E} 5$ of $E$. multilocularis was recorded, whereas in isolate from Vaslui county three nucleotide substitutions were detected as compared to the most related E5 haplotype. One of these mutations (411T/G) matched N1 and N2 haplotypes described previously from North America. In six CE samples retrieved from western Romania (Caras-Severin and Timis counties), two human isolates were diagnosed as Echinococcus canadensis G7, one as E. granulosus s.s. G1 and one as E. granulosus s.s. G3 using atp6 and rrnS sequencing. In ungulates, the cattle isolate was allocated to $E$. granulosus s.s. G1 and pig isolate to $E$. canadensis $\mathrm{G} 7$. The two $\mathrm{G} 7$ findings in humans reinforced the recent view that $\mathrm{G} 7$ was underestimated as compared to the $E$. granulosus s.s. regarding human CE threat that can be further employed for identifying sources of infections and establishing suitable preventive measures.
\end{abstract}

Keywords: Echinococcus; Romania; genotype; human; cattle; pig

\section{Introduction}

Cystic echinococcosis (CE) and alveolar echinococcosis (AE) caused by E. granulosus sensu lato and Echinococcus multilocularis, respectively, present substantial disease burden and public health economic problem in many parts of the world. In developed countries, human $\mathrm{CE}$ is more common than $\mathrm{AE} ; 77.5 \%$ of
601 confirmed cases of echinococcosis with species information available for Europe in 2015 were caused by E. granulosus s.l. as compared to E. multilocularis (EFSA, 2016). In some countries of Eastern Europe and the former Soviet Union (Bulgaria, Romania, Kazakhstan), zoonotic CE infections are emergent since the early 1990's, with burden approximately four fold times higher than during administration of previous political system (Todorov \&

\footnotetext{
$\bar{*}$ - corresponding author
} 
Boeva, 1999; Torgerson \& MacPherson, 2011). The increased CE occurrence in these regions is mainly due to neglect or collapse of veterinary control services and changes in typology of animal husbandry drifted from intensive to familiar management (Battelli, 2009). Romania has been ranked in the forefront of the European countries in the number of human and animal cases of echinococcosis in the mid 1990's (Neghina et al., 2010). Since 2001, the prevalences of CE infection in livestock animals of Romania varied between $12.7 \%$ and $65.6 \%$ in sheep, $19 \%$ and $40.1 \%$ in cattle, $3.8 \%$ and $6.5 \%$ in pig, and $9.5 \%$ and $12.1 \%$ in horses (lacobiciu et al., 2005; Mitrea et al., 2010, 2012, 2014).

Genetic variability in the $E$. granulosus s.l. species complex is well perceived as influencing infectivity in humans, intermediate host affiliations, development rate and other biological characteristics of the parasites (Alvarez Rojas et al., 2014). The complex is considered to include genotypes G1-G8, G10 encompassing at least four species currently recognized ( $E$. granulosus sensu stricto, E. equinus, E. ortleppi, E. canadensis), and E. felidis (Romig et al., 2015). Recently, genotype $G 2$ of $E$. granulosus s.s. was recommended to be deleted from the genotype list based on the complex mitogenome and nuclear evidence (Kinkar et al., 2017).

According to the latest records, the known range of E. multilocularis has markedly extended across Europe and it is assumed to be currently distributed over the most of its territory. For countries of central-eastern Europe, evidence supports northward and southeastern expansions from a core endemic area in south-central Europe as documented by findings from Poland, Baltic countries, Slovakia, Hungary, Romania (summarized in Davidson et al., 2012 and Oksanen et al., 2016). Prevalence trends of AE in humans appear to follow the surge in parasite abundance in wildlife coinciding with dramatic increases of fox population that began since 1990's (Mackenstedt et al., 2015). In several European countries, the steady rise of human $A E$ cases was documented over the last two decades at least in some regions (e.g., Schweiger et al., 2007; Said-Ali et al., 2013; Marcinkutè et al., 2015). For Romania, recent data suggest spreading and emergence of $E$. multilocularis where a mean prevalence of $4.8 \%$ was found in red foxes from Transylvanian counties in central and north-western parts of the country (Sikó et al., 2011). Transmission of the parasite to humans was confirmed by two cases of $\mathrm{AE}$ in patients in past (Panaitescu \& Pop, 1999; Savlovschi, 2000). Nevertheless, information about genetic variants of $E$. multilocularis circulating in Romania is lacking. The present study was conducted to identify Echinococcus spp. from western and north-eastern regions of Romania derived from human, cattle and pig intermediate hosts and to examine haplotype microvariants that circulate in respective areas.

\section{Materials and Methods}

A total of 11 Echinococcus isolates (nine human and two ungulate isolates) derived from five counties in north-eastern Romania (lasi, Botosani, Vaslui) and western Romania (Caras-Severin, Timis) were included in this study (characteristics of the isolates are in Table 1). Sampling sites from which isolates were collected are shown in Fig. 1. Fertile hydatid isolates with viable protoscoleces from cattle and pig livers were recovered from abattoir and household in Caras-Severin county of western Romania. Human cysts were excised or drained during conventional surgical intervention of patients in north-eastern Romania and western Romania. Nine human isolates were obtained from livers and one from lungs in surgical departments of hospitals in lasi (north-eastern Romania) and Timisoara (western Romania). Six patients were females and three were males. The age of the patients has ranged from 17 to 67 years. Cyst contents were examined under light microscopy for the presence of protoscoleces, rinsed in physiological saline and fixed in $70 \%$ ethanol prior to molecular analyses.

Total genomic DNA was retrieved from protoscoleces or germinal layer using the DNeasy tissue kit (QIAGEN, Germany) according to the manufacturer's instructions. Three mitochondrial genes were targeted for PCR amplifications employed in two different

Table 1. Echinococcus isolates used in this study.

\begin{tabular}{lllcll}
\hline Isolate & Host & Geographical origin & Age in years, sex & Organ & Additional characteristics \\
\hline R1 & human & lasi, lasi county & $36, \mathrm{~F}$ & Liver & urban, unemployed \\
R2 & human & lasi, lasi county & $17, \mathrm{~F}$ & Liver & $\begin{array}{l}\text { urban, student (often visited the grandparent's } \\
\text { house in the countryside) }\end{array}$ \\
& & & & & (ald \\
R3 & human & Baltati, lasi county & $51, \mathrm{~F}$ & Liver & rural, farmer (dog, no sheep) \\
R4 & human & Botosani, Botosani county & $45, \mathrm{M}$ & Liver & rural, farmer (sheep, goats) \\
R5 & human & Tutova, Vaslui county & $67, \mathrm{M}$ & Liver & rural, farmer \\
R6 & human & Timis county & $32, \mathrm{~F}$ & Liver & urban, employed in meat industry \\
R7 & human & Caras-Severin county & $20, \mathrm{M}$ & Lung & rural, shepherd \\
R8 & human & Caras-Severin county & $41, \mathrm{~F}$ & Liver & rural, unemployed \\
R9 & human & Caras-Severin county & $55, \mathrm{~F}$ & Liver & rural, office worker \\
R10 & cattle & Caras-Severin county & & Liver & rural, abattoir \\
R11 & pig & Caras-Severin county & & Liver & rural, household system \\
\hline
\end{tabular}




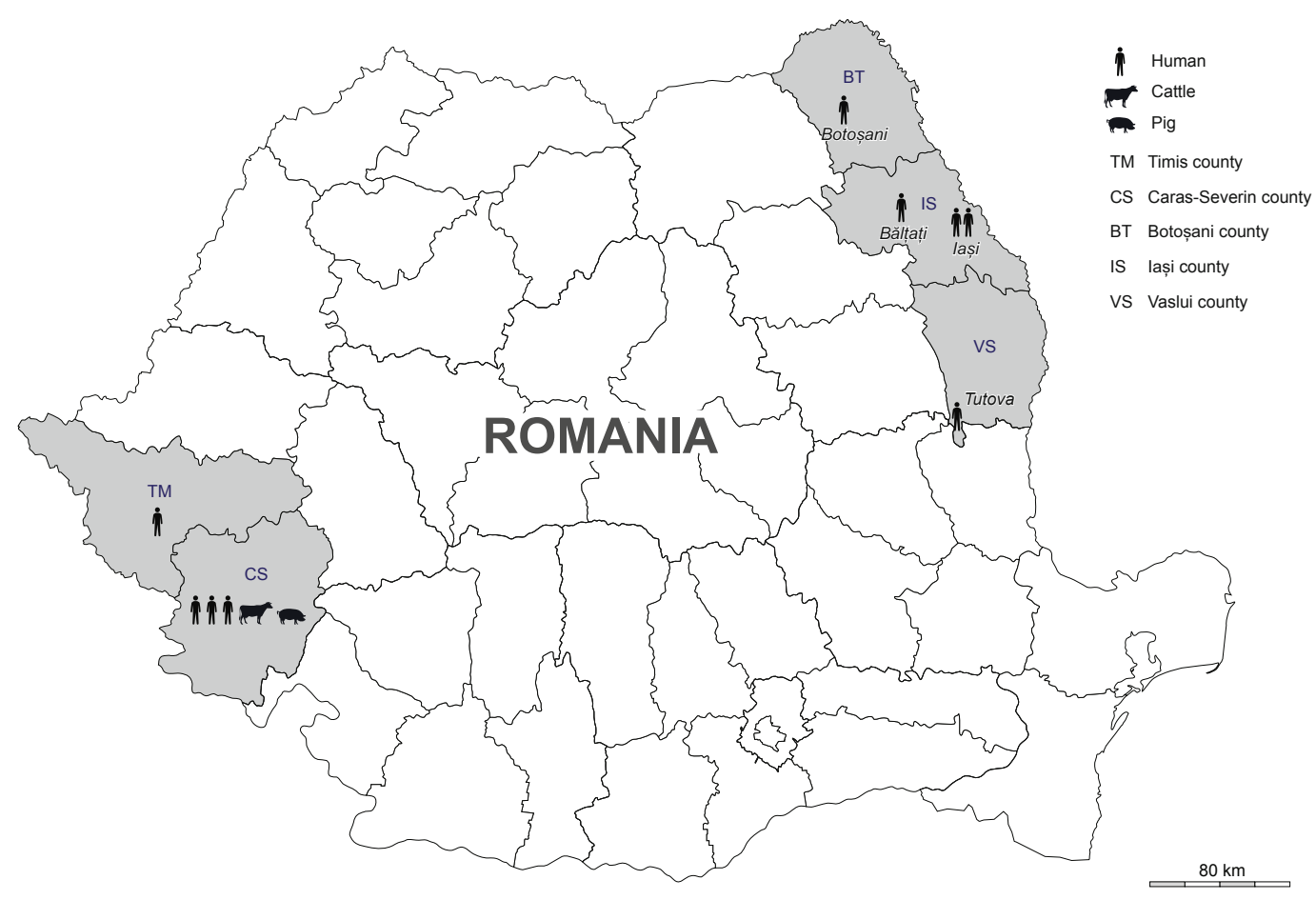

Fig. 1. Geographic locations of Echinococcus samples from Romania used in the study.

time periods after the sample recoveries. For samples obtained from north-eastern Romania resulting as $E$. multilocularis, partial cytochrome $c$ oxidase 1 gene (cox1, 789 bp) was analyzed using primers described by Xiao et al. (2003). For samples obtained from western Romania resulting as E. granulosus s.l., partial ATP synthase subunit 6 (atp6, $513 \mathrm{bp}$ ) and 12S rRNA ( $r r n S, 295 \mathrm{bp}$ ) genes were examined using primers described by Xiao et al. (2005) and Dinkel et al. (1998). The PCR conditions were as follows: initial denaturation at $95^{\circ} \mathrm{C}$ for $5 \mathrm{~min}, 35$ cycles at $94^{\circ} \mathrm{C}$ for $30 \mathrm{~s}, 55^{\circ} \mathrm{C}$ for $30 \mathrm{~s}$, and $72{ }^{\circ} \mathrm{C}$ for $1 \mathrm{~min}$; followed by a final extension at $72{ }^{\circ} \mathrm{C}$ for $5 \mathrm{~min}$. PCR products were visualized after electrophoresis on $1.5 \%$ (w/v) agarose gels and purified using a Nucleospin Extract II kit (Macherey Nagel, Düren, Germany). Amplicons were sequenced in both directions using a dye terminator cycle sequencing kit (DYEnamic ET terminator; Amersham Biosciences, UK) and analysed with an ABI PRISM 377 automated sequencer (Applied Biosystems, USA). Generated sequences were manually edited, aligned and compared to reference GenBank sequences by nucleotide BLASTN program (https://blast.ncbi.nlm.nih.gov). The branching pattern was generated by MEGA7 software (Kumar et al., 2016) using the neighbor-joining (N-J) method, selecting the most reliable evolutionary method (TN93) according to ModelTest performed under the Bayesian Information Criterion (BIS). Bootstrap analyses were conducted by using 1000 replicates. To infer reticulate evolutionary relationships among specimens of $E$. multilocularis here analysed, median joining network (Bandelt et al., 1999) and parsimony network (Clement et al., 2002) were constructed using PopART software (http://popart.otago.ac.nz). EM-
BOSS Transeq tool (http://www.ebi.ac.uk/emboss/transeq) was used for translation nucleotide sequence into a protein sequence to distinguish synonymous and non-synonymous mutations. The sequences obtained in this study were deposited in GenBank under the accession numbers MF162277-MF162293.

\section{Results}

In this study DNA extracted from 11 Echinococcus isolates originating from 9 human hosts and 2 animal hosts in Romania was PCR amplified. Species and genotype analyses using the BLAST algorithm identified 5 isolates from humans as $E$. multilocularis, 2 isolates from humans as $E$. granulosus s.s. (G1 and G3 genotypes), 2 isolates from humans as $E$. canadensis ( $\mathrm{G} 7$ genotype), 1 isolate from cattle as $E$. granulosus s.s. (G1 genotype) and 1 isolate from pig as $E$. canadensis (G7 genotype).

Five Echinococcus isolates from humans in north-eastern Romania were analyzed by cox1 mitochondrial sequences (789 bp). Given that species analysis of nucleotide composition identified E. multilocularis in all examined isolates, we have compared obtained sequences with those referenced by Nakao et al. (2009) in a study on global species geographic pattern and available in GenBank for cox1 from Europe (E1, E3, E5), Asia (A1, A5) and North America (N1, N2). Polymorphic nucleotide sites are shown in Table 2. Resulting cox1 haplotypes for four Romanian isolates (R1-R4) were identical to the E5 isolate (referenced from Slovakia), which represents the most common European variant of E. multilocularis. For the R5 isolate derived from Vaslui county, three nucleotide 
Table 2. Nucleotide differences in cytochrome c oxidase subunit 1 among Echinococcus multilocularis isolates.

\begin{tabular}{|c|c|c|c|c|c|c|c|c|c|c|c|c|c|c|}
\hline $\begin{array}{l}\text { Position in cox1 } \\
\text { Isolate (origin, accession numbers) }\end{array}$ & 12 & 22 & 40 & 44 & 261 & 351 & 364 & 399 & 411 & 436 & 476 & 498 & 531 & 602 \\
\hline R1-R4 (Romania) & $A$ & $T$ & G & C & G & G & $\mathrm{T}$ & G & $\mathrm{T}$ & $A$ & $C$ & $A$ & $\mathrm{~T}$ & C \\
\hline R5 (Romania) & . & . & . & . & . & . & . & $\mathrm{T}$ & G & . & . & . & C & . \\
\hline E1 (Austria, GBr AB461412) & . & C & $\mathrm{T}$ & . & . & . & . & . & . & . & . & . & . & . \\
\hline E3 (France, GBr AB461413) & . & . & . & $\mathrm{T}$ & . & . & . & . & . & . & . & . & . & . \\
\hline E5 (Slovakia, GBr AB461414) & . & . & . & . & . & . & . & . & . & . & . & . & . & . \\
\hline A1 (Kazakhstan, GBr AB461415) & . & . & . & . & . & $\mathrm{T}$ & C & . & . & . & . & . & . & G \\
\hline A5 (China, GBr AB461417) & . & . & 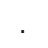 & & . & $\mathrm{T}$ & C & . & . & . & . & G & . & . \\
\hline N1 (St. Lawrence Island, USA, GBr AB461418) & G & . & . & . & . & $\mathrm{T}$ & . & . & G & . & $\mathrm{T}$ & G & . & . \\
\hline N2 (Indiana, USA, GBr AB461419) & . & . & . & . & $A$ & $T$ & . & . & G & G & $T$ & G & . & . \\
\hline
\end{tabular}

Only positions with differences between isolates are shown. Identical nucleotides are represented by dots.

substitutions (accounting for $0.38 \%$ divergence) were recorded as compared to the most related $\mathrm{E} 5$ haplotype. These mutations, namely 399G/T, 411T/G and 531T/C, were synonymous. One of these mutations (at position 411) matched N1 and N2 haplotypes from North America, whereas remaining mutations were unique. Four and five nucleotide differences, respectively, were found in the R5 compared with the additional referenced sequences from Europe, E3 (France) and E1 (Austria), respectively. However, all
European samples clustered together in the resulting dendrogram, being separated by sufficiently supported clade (bootstrap value of $68 \%$ ) from Asian and North American samples (Fig. 2). Pairwise divergences of the R5 isolate in relation to Asian and North American haplogroups were identical $(6-7$ differences to reference couples accounting for $0.76-0.89 \%$ divergence). The structure of phylogenetic haplotype network for $E$. multilocularis isolates in cox1 is illustrated in Fig. 3.

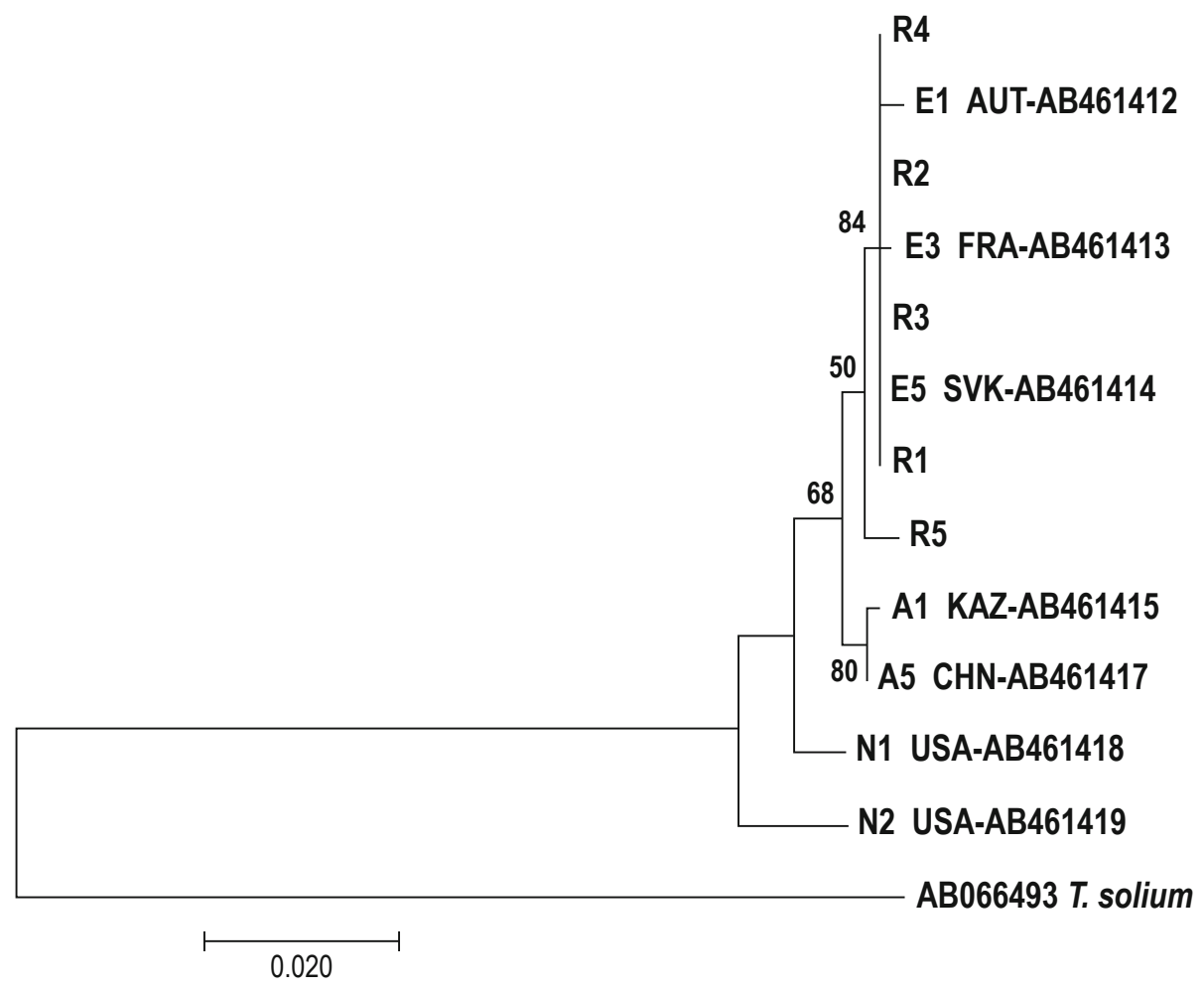

Fig. 2. Neighbor-joining tree inferred from cox1 (789 bp) sequences showing the relationships among the Echinococcus multilocularis isolates from Romania (R1-R5) in comparison to GenBank retrieved reference sequences. Taenia solium was used as outgroup. The percentage of replicate trees in which the associated taxa clustered together in the bootstrap test are shown next to the branches. The tree is drawn to scale, with branch lengths proportional to the evolutionary distances. 


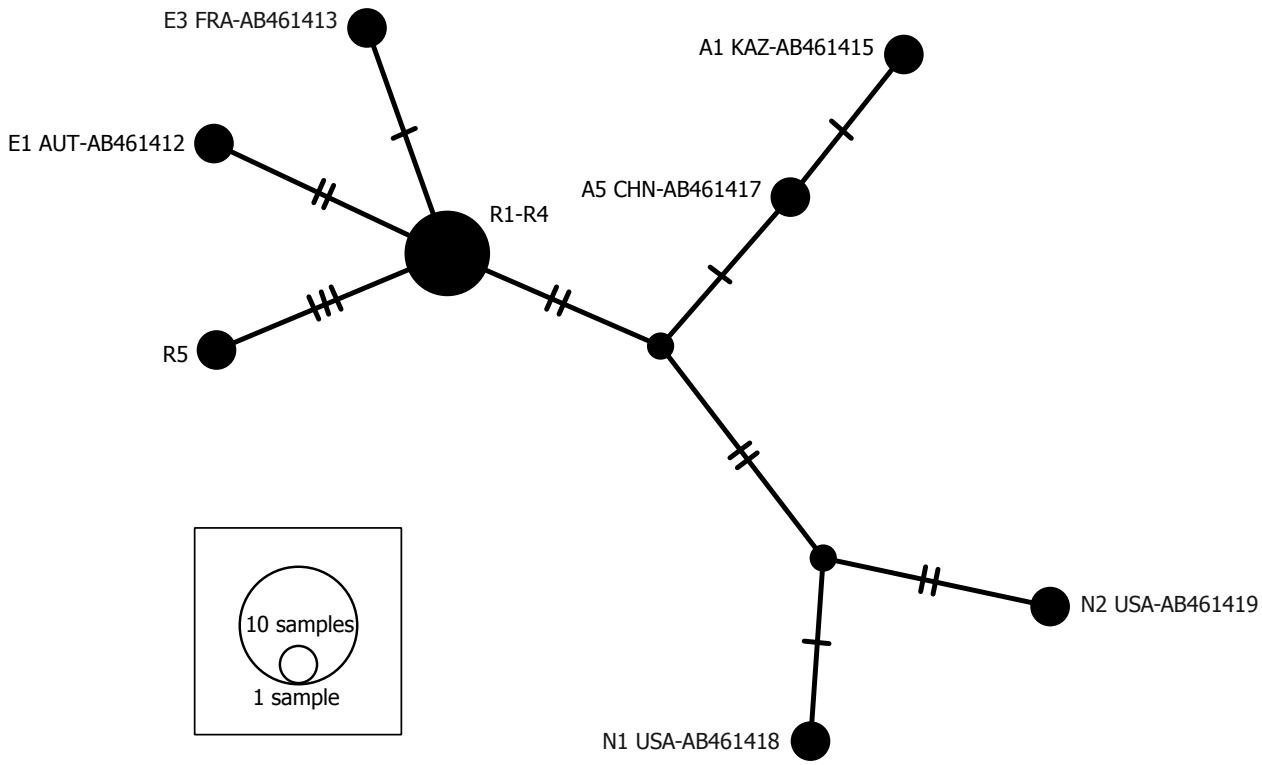

Fig. 3. Haplotype network of Echinococcus multilocularis isolates based on cox1 sequences. Diameters of circles are proportional to haplotype frequencies, transversal bars at branches represent point mutations, black dots without sample code indicate extant haplotypes.

In the study conducted on 6 isolates (4 from humans and 2 from domestic ungulates) collected from the two counties in western Romania (Caras-Severin, Timis) in mitochondrial atp6 and $r r n S$ gene fragments, within human isolates two were identified as E. canadensis $\mathrm{G} 7$, one isolate as $E$. granulosus s.s. $\mathrm{G} 1$, and one isolate as $E$. granulosus s.s. G3. For ungulates, the pig isolate was defined as possessing the $E$. canadensis $\mathrm{G} 7$ structure and the cattle isolate exhibited the E. granulosus G1 structure. Resulting E. granulosus s.l. genotypes from samples in western Romania are specified in Table 3.

In the atp6 gene portion (513 bp), three samples showed the pattern characteristic for $E$. granulosus s.s. Amongst them, nucleotide composition of R6 and R9 human isolates was identical to the E. granulosus G1-G3 reference bases (GBr AF297617). In addition, the R10 isolate from cattle manifested two base differences, specifically the $342 \mathrm{~T} / \mathrm{C}$ synonymous substitution and the $379 \mathrm{G} / \mathrm{A}$ non-synonymous substitution (alanine/threonine). These mutations were previously found according to the data on the NCBI

Table 3. Genotypic classification of $E$. granulosus isolates from western Romania.

\begin{tabular}{lllccc} 
Isolate & Host & Geographical origin & atp6 & rrns & $\begin{array}{c}\text { Final } \\
\text { genotype }\end{array}$ \\
\hline R6 & human & Timis county & G1-G3 & G1 & G1 \\
R7 & human & Caras-Severin county & G7A & G7 & G7 \\
R8 & human & Caras-Severin county & G7 & G7 & G7 \\
R9 & human & Caras-Severin county & G1-G3 & G3 & G3 \\
R10 & cattle & Caras-Severin county & G1-G3 & G1 & G1 \\
R11 & pig & Caras-Severin county & G7 & G7 & G7 \\
\hline
\end{tabular}

database in the Indian sheep isolate (GBr EF394904), and in the Turkish sheep isolate (Šnábel et al., 2009). The atp6 pattern of the three additional isolates was allocated to $E$. canadensis $\mathrm{G} 7$. Of these, sequences of the R8 (human) and the R11 (pig) isolates entirely matched the $\mathrm{G} 7$ reference ( $\mathrm{GBr}$ AY056614). The R7 human isolate exhibited one nucleotide difference $238 \mathrm{G} / \mathrm{T}$, corresponding to non-synonymous substitution of alanine/serine (this haplotype is herein referred to as G7A for atp6).

To differentiate between genotypes of $E$. granulosus s.s. (atp6 gene allows only for diagnosis at species level of $E$. granulosus s.I.), rrnS gene (295 bp) with resolving power to discriminate G1/G3 genotypes was screened. Fixed nucleotide exchanges 166T/G and $205 \mathrm{~A} / \mathrm{G}$ had delineated the R6 human-derived isolate and the $\mathrm{R} 10$ cattle-derived isolate as bearing $\mathrm{G} 1$ genotype and the $\mathrm{R} 9$ human-derived isolate as bearing $\mathrm{G} 3$ genotype. Monomorphic patterns of the remaining $\mathrm{R} 7, \mathrm{R} 8$ and $\mathrm{R} 11$ isolates from humans and pig were identical to the $G 7$ reference for rrnS (GBr AY462128), thus definitely confirming their genotypic status. A list of diagnosed genotypes in western Romania is provided in Table 3.

\section{Discussion}

The present study provides the first report on the genetic characterization of $E$. multilocularis in clinical samples of five patients from north-eastern Romania. In addition, the present data add further evidence for the transmission of $E$. granulosus s.s. and $E$. canadensis $\mathrm{G} 7$ in humans and domestic ungulates in the western part of the country.

In Romania, E. multilocularis was firstly detected in rodents during surveys conducted in 1991 - 1995 in the subalpine region of the 
East Carpathian Mountains (counties Harghita and Covasna in central Romania). Prevalence rates ranged from $0.44 \%$ to $1.67 \%$ in four species of 2,416 examined rodents (Sikó, 1992, 1993; Sikó et al., 1995). Nevertheless, until 2002 E. multilocularis was not detected neither in 535 red foxes from one of the study areas (Covasna) nor in 50 foxes from three other counties (Brasov, Cluj, Mures) (Sikó et al., 1995; Gherman et al., 2002). However, in the first complex investigation of the fox population from the large part of Romania the parasite was found in $4.8 \%$ (27/561) of red foxes in 8 of 15 counties (Sikó et al., 2011). The highest $E$. multilocularis prevalences of $10.5-14.6 \%$ were found in the counties bordering Hungary and Ukraine, with a tendency of decreasing prevalences towards the central parts. Three adjacent counties in north-eastern Romania allocated to geographical historical region of Western Moldavia (lasi, Vaslui, Botosani), from which our patients originated, were not included in this fox survey. The question arises from where the parasite may have been introduced into these areas. In Ukraine neighboring northward to Western Moldavia, Kharchenko et al. (2008) recorded E. multilocularis in $28.8 \%$ (4/14) of foxes. Two foxes collected in both foci in Volyn and Lviv oblasts of western Ukraine were found to be infected. Of these, the latter focus in Staryi Sambir forestry is located closer to Romanian areas with positive patients, but yet in a relatively long distance of approx. $400 \mathrm{~km}$. Moreover, failure to detect metacestodes of the parasite in small mammal populations and lack of reported human AE cases indicate the recent introduction of the parasite in the country, likely connected to migrating fox populations from endemic areas of Hungary, Poland, or Slovakia (Szilágyiová et al., 2015). In Harghita, Bistrita and Covasna counties in central-northern Romania (located $150-250 \mathrm{~km}$ apart from sites of our AE patients), infection rates of $1.69-5.66 \%$ were measured in the above study of Sikó et al. (2011). It is thus plausible that E. multilocularis is being transmitted in some portion via red foxes also in north-eastern Romania. The Moldova Republic neighboring eastward is classified as a country with uncertain endemicity status (Oksanen et al., 2016; EFSA, 2016), having a single record of $E$. multilocularis from house mouse in 1961 (Abuladze, 1964; Bessonov, 2002). Nevertheless, the country is believed to be endemic for the parasite over at least part of its territory, with 1 estimated annual number of human cases according to Torgerson et al. (2010).

For Romania, the compiled number of $\mathrm{AE}$ and $\mathrm{CE}$ human cases recorded in the EU summary reports has decreased in 2011 - 2015 from 0.27 to 0.09 per 100.000 population, with 18 cases registered in 2015 (EFSA, 2016). Although the exact proportion of human $A E$ cases is unknown from EFSA reports, some AE cases in Romanian patients could have been misclassified as CE, because the notion that cystic echinococcosis is endemic in Romania is more common. Only two cases of $A E$ in patients, originated from north-western Romania (Bihor county) (Panaitescu \& Pop, 1999) and from central Romania (Sibiu county) (Savlovschi, 2000), were previously documented in the country. In the first infection, the liver was parasitized and the disease was serologically confirmed at
Cantacuzino Institute in Bucharest. Later, the serum was tested repeatedly abroad and was confirmed to be highly positive. The second case was recorded in the spleen of a 49-year-old patient during a surgical operation (lacobiciu et al., 2005). To the best of our knowledge the present study provides the first molecular evidence of $E$. multilocularis in Romanian humans.

Age at the diagnosis of five herein AE-affected persons in northeastern Romania ranged from 17 to 67 years (mean age 43.2). Three of $5 \mathrm{AE}$ affected patients were farmers and one case was associated with a 17-year-old student who has regularly spent some time at the grandparent's countryside house. This is in agreement with the summarized data for $\mathrm{AE}$ patients from Europe of Kern et al. (2003) who reported $61.4 \%$ of 210 patients as involved in vocational or part-time farming, gardening, forestry, or hunting. Three patients infected with AE originated from the two sites of the lasi county, and one patient was diagnosed from both Botoșani and Vaslui counties. Whereas the sequence pattern of four isolates was completely homologous to the most widespread variant of $E$. multilocularis identified for Europe in the cox1 gene, one isolate (R5) at the southernmost location (Tutova, Vaslui county) amongst the examined samples exhibited three nucleotide substitutions. Interestingly, one of these mutations (411T/G) corresponded to N1 and N2 haplotypes from North America described by Nakao et al. (2009) and to an older human isolate from Austria obtained upon hepatic surgery in 1981 (Gottstein, personal communication; genotyping of the isolate specified in Šnábel et al., 2010). The peculiar genetic composition of $E$. multilocularis seen in some restricted foci of Europe as Trentino Alto Adige region (Casulli et al., 2005, 2009) and in the present isolate from Vaslui county, coupled with the discontinuous distribution of the parasite in recent Europe supports a hypothesis that the European clade has been derived from isolated populations in glacial refugia such as the Italian, Balkan and Iberian peninsulas (Taberlet et al., 1998). Given that the same nucleotide substitution was detected in the North American clade and the two European isolates from distinct sites (Austria, Romania), retention of the shared ancestral polymorphism due to incomplete lineage sorting seems to be plausible explanation for this pattern. Molecular evidence for natural selection imposed on cox1 has not been indicated because the nucleotide differences present in the R5 isolate did not lead to amino acid substitutions. Generally, lower genetic diversity, including founder effects, was recorded in peripheral areas of the endemic zone of Europe in several recent studies (Šnábel et al., 2006; Bagrade et al., 2008; Casulli et al., 2009; Knapp et al., 2010).

The molecular discrimination of the species and strains of Echinococcus granulosus s.l. are major prerequisites for effective control programs. Five of six hydatid samples genetically typed here originated from Caras-Severin county in western Romania. During 2004 - 2010, an incidence rate of 4.4 cases $/ 100,000$ inhabitants was recorded in Caras-Severin that was higher as compared to the period of 1987 - 1991 during which 3 cases/100,000 inha- 
bitants were reported (Sikó et al., 2002; Moldovan et al., 2012). The authors explained this rise by the massive increases in the number of stray dogs (with a concomitant poorer control of them) and dog owners during the post-communist period after 1990. Consistently with this issue, Piccoli et al. (2013) indicated as main risk for acquiring $\mathrm{CE}$ infection close contact with stray dogs, which potentially experienced $96.7 \%$ of 60 patients in south-eastern Romania. As reviewed by Neghina et al. (2010), the average prevalence of CE infection in dogs was quite high during the surveyed period $1956-1992(21.6 \%$, the range of $0-83 \%$ in the Romanian regions). More recent data obtained in the observation period 2005 - 2008 measured prevalence rates in dogs from rural areas in the range of $12.5 \%-19.2 \%$ (Seres et al., 2006; Seres et al., 2010). The ongoing active transmission of $E$. granulosus in Romania is seen particularly in areas where pastoral activities are concentrated. Unsupervised home slaughtering of livestock still present especially for sheep and pigs, frequent absence of appropriate anthelmintic treatment of dogs and the above mentioned parasite dispersal by stray dogs are likely to be the most important factors maintaining transmission cycle of the tapeworm in the country (Mitrea et al., 2012).

Among the three human isolates derived from Caras-Severin, two were identified as $E$. canadensis $G 7$ and one belonged to $E$. granulosus s.s. G3. The human isolate recovered from the adjacent Timis county was classified as E. granulosus s.s. G1. Amongst isolates retrieved from domestic ungulates in CarasSeverin county, one cattle was allocated to E. granulosus G1 and one pig isolate to $E$. canadensis $\mathrm{G} 7$. The presence of $E$. granulosus G1-G3 complex (E. granulosus s.s.) coincides with areas of high CE prevalence, whereas for $E$. canadensis G6/G7 a low infectivity for humans was suggested because case numbers are usually low in regions where these genotypes predominate (Romig et al., 2015). In a recent phylogeographical study of Kinkar et al. (2016) on Mediterraenan and South European E. granulosus s.s. $\mathrm{G} 1$, Romanian cattle isolate was genetically most closely related to Turkish samples derived from one of central haplotypes than to geographically more close samples. This indicated a substantial role of livestock trade, which has facilitated the parasite dispersal over vast areas, in shaping phylogeographical G1 pattern.

In connection with a single human sample identified here as $E$. granulosus G3, a relatively high proportion of the G3 genotype ( $28.2 \%, 46$ of 163 isolates) in the samples typed as E. granulosus S.S. was before detected in Romania when markers with the G1G3 resolution power were used (Bart et al., 2006; Badaraco et al., 2008; Maillard et al., 2009; Casulli et al., 2012; Mitrea et al., 2014; Šnábel et al., 2016). This genetic form was found in sheep, cattle and pig in the country, whereas the present finding provides the first report of G3 in humans from Romania. High rates of G3 infections within $E$. granulosus s.s. were recently recorded also in neighboring Serbia (40\%, 18 of 40 isolates) and Bulgaria (46.7 \%, 14 of 30 isolates) (Debeljak et al., 2016; Marinova et al., 2017). Interestingly, in two of the four human samples $E$. canadensis $\mathrm{G} 7$ was diagnosed as CE causative agent. Before, only a single G7 case was detected by Piccoli et al. (2013) amongst 68 typed human isolates in Romania. Patients and pigs infected with $\mathrm{G} 7$ have smaller cysts than those infected with $\mathrm{G} 1$, therefore the human infections are being more often identified incidentally (Turčeková et al., 2009; Schneider et al., 2010). Pig constitutes a significant reservoir for maintaining transmission pattern in Romania and the number of G7-registered human cases is likely to be underestimated. Although genotypes of $E$. canadensis are of minor relevance for human health compared to E. granulosus s.S., the estimated contribution of $11.07 \%$ (184 of 1661 human cases) to global CE disease according to the worldwide synopsis is not negligible (Alvarez Rojas et al., 2014).

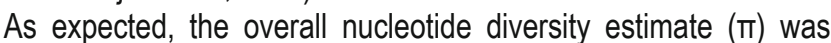
markedly higher for six $E$. granulosus s.l. examined Romanian isolates (0.0702) than for five E. multilocularis isolates (0.0196). Lower genetic variability in $E$. multilocularis is putatively due to the facts that $E$. multilocularis has conservative host spectrum compared to $E$. granulosus adapted to a number of different host species and that $E$. multilocularis is phylogenetically young species (Haag et al., 1997; Bart et al., 2003).

More effective public health policies to reduce E. granulosus s.l. transmission should be implemented in Romania, also with regard to prevent precursors to regional and global expansions associated with trade. For example, in 2007 the country accounted for $90 \%$ of all Echinococcus positive cattle imported to the Netherlands, the number of which has increased since the accession of the country to the European Union (Berends et al., 2009). Further investigations of genetic and epidemiological issues on greater number of samples in various areas are needed to better clarify the transmission ecology and geographic pattern of CE and AE in Romania.

\section{Acknowledgements}

The study was supported by the Scientific Grant Agency VEGA (project No. 2/0162/17) (P 0.6) and the project "INFEKTZOON Centre of Excellence For Animal Infections and Zoonoses (ITMS26220120002)"(P 0.4). A part of results was obtained via mobility grant of the Japan Society for Promotion of Science (JSPS) (ID No. RC 20728104) and research JSPS grants Nos. 14256001, 17256002.

\section{References}

Abuladze, K.I. (1964): Taeniata - the tapeworms of animals and man and diseases cause by them. In: SKRJABIN A.K.I. (Ed.) Essentials of Cestodology. Volume IV. Moscow: Nauka, 1964, 530 pp. (In Russian)

Alvarez Rojas, C.A., Romig, T., Lightowlers, M.W. (2014): Echinococcus granulosus sensu lato genotypes infecting humans - review of current knowledge. Int. J. Parasitol., 44(1): 9 - 18. DOI: 10.1016/j.jpara.2013.08.008 
Badaraco, J.L., Ayala, F.J., Bart, J.M., Gottstein, B., Haag, K.L. (2008): Using mitochondrial and nuclear markers to evaluate the degree of genetic cohesion among Echinococcus populations. Exp. Parasitol., 119(4): 453 - 459. DOI: 10.1016/j.exppara.2008.02.004

Bandelt, H., Forster, P., RöHl, A. (1999): Median-joining networks for inferring intraspecific phylogenies. Mol. Biol. Evol., 16(1): 37 48. DOI: 10.1093/oxfordjournals.molbev.a026036

Bagrade, G., Šnábel, V., Romig, T., Ozolinš̌, J., Hüttner, M., MiterpáKovÁ, M., ŠEvcovÁ, D., DuBINSKÝ, P. (2008): Echinococus multilocularis is a frequent parasite of red foxes (Vulpes vulpes) in Latvia. Helminthologia, 45(4): 157 - 161. DOI: 10.2478/s11687-008-0032-1

Bart, J.M., Breyer, I., Gottstein, B., Romig, T., Piarroux, R. (2003): Development of molecular tools to explore genetic diversity in Echinococcus multilocularis. Helminthologia, 40(2): 117 - 121

Bart, J.M., Morariu, S., Knapp, J., llie, M.S., Pitulescu, M, Anghel, A., Cosoroaba, I, Piarroux, R. (2006): Genetic typing of Echinococcus granulosus in Romania. Parasitol. Res., 98(2): 130 - 137. DOI: $10.1007 /$ s00436-005-0015-9

BAtTell, G. (2009): Echinococcosis: costs, losses and social consequences of a neglected zoonosis. Vet. Res. Commun., 33 (Suppl 1): S47 - S52. DOI: 10.1007/s11259-009-9247-y

Berends, I.M.., Holzhauer, M., van der Giessen, J.W.B., van Schaik, G. (2009): Risk of Echinococcus granulosus becoming endemic in Dutch cattle. Tijdschr. Diergeneesk, 134(3): 104 - 109. (In Dutch) BEssonov, A.S. (2002): Echinococcoses of animals and humans in the Russian Federation. In: CRaIG, P.S., Pawlowski, Z. (Eds) Cestode Zoonoses: an emergent and global problem. NATO Sciences Series, 341: pp. $91-98$

Casulli, A., Manfredi, M.T., La Rosa, G., Di Cerbo, A.R., Dinkel, A., Romig, T., Deplazes P., Genchi, C., Pozio, E. (2005): Echinococcus multilocularis in red foxes (Vulpes vulpes) of the Italian Alpine region: is there a focus of autochthonous transmission? Int. J. Parasitol., 35(10): 1079 - 1083. DOI: 10.1016/j.jpara.2005.04.005

Casulli, A., Bart, J.M., Knapp, J, La Rosa, G., Dusher, G., Gottstein, B., Di Cerbo, A., Manfredi, M.T., Genchi, C., Piarroux, R., Pozio, E. (2009): Multi-locus microsatellite analysis supports the hypothesis of an autochthonous focus of Echinococcus multilocularis in northern Italy. Int. J. Parasitol., 39 (7): 837 842. DOI: 10.1016/j. ijpara.2008.12.001

Casulli, A., Interisano, M., Sréter, T., Chitimia, L., Kirkova, Z., La RosA, G., Pozıo, E. (2012): Genetic variability of Echinococcus granulosus sensu stricto in Europe inferred by mitochondrial DNA sequences. Infect. Genet. Evol., 12(2): 377 - 383. DOI: 10.1016/j. meegid.2011.12.014

Clement, M., Posada, D., Crandall, K.A. (2002): TCS: a computer program to estimate gene genealogies. Mol. Ecol., 9(10): 1657 1659. DOI: 10.1046/j.1365-294x.2000.01020.x

Debeljak, Z., Boufana, B., Interisano, M., Vidanovic, D., Kulisic, Z., CAsulLI, A. (2016): First insights into the genetic diversity of Echinococcus granulosus sensu stricto (s.s.) in Serbia. Vet. Parasitol., 223: 57 - 62. DOI: 10.1016/j.vetpar.2016.04.007.
Davidson, R.K., Romig, T., Jenkins, E., Tryland, M., Robertson, L.J. (2012): The impact of globalisation on the distribution of Echinococcus multilocularis. Trends Parasitol., 28(6): 239 - 247. DOI: 10.1016/j.pt.2012.03.004

Dinkel, A., von Nickisch-Rosenegk, M., Bilger, B., Merli, M., Lucius, R., Romig, T. (1998): Detection of Echinococcus multilocularis in the definitive host: coprodiagnosis by PCR as an alternative to necropsy. J. Clin. Microbiol., 36(7): 1871 - 1876

European Food Safety Authority (EFSA) (2016): The European Union summary report on trends and sources of zoonoses, zoonotic agents and food-borne outbreaks in 2015. EFSA J. 14(12): 4634, https://www.efsa.europa.eu/en/efsajournal/pub/4634

Gherman, C., Cozma, V., Mircean, V., Brudasca, F., Rus, N., Detasan, A. (2002): Helminthic zoonoses in wild carnivours species from Romanian fauna. Scient. Parasitol., 3(2): 17 - 21 (In Romanian) HaAg, K.L., Zaha, A., Araujo, A.M., Gottstein, B. (1997): Reduced genetic variability within coding and non-coding regions of the Echinococcus multilocularis genome. Parasitology, 115: Part 5, $521-529$

Iacobiciu, I., Stefanescu, V., Sikó Barabási, S., Corolu, Z. (2005): Epidemiologia echinococozei-hidatidozei [Epidemiology of echinococcosis-hydatidosis]. Sfantu Gheorghe: SC Tipo Graf, SRI. (In Romanian)

Kern, P., Bardonnet, K., Renner, E., Auer, H., Pawlowski, Z., Ammann, R.W., Vuitton, D.A., Kern, P., European Echinococcosis RegISTRY (2003): European echinococcosis registry: human alveolar echinococcosis, Europe, 1982 - 2000. Emerg Infect Dis., 9(3): 343 - 349. DOI: 10.3201/eid0903.020341

Kharchenko, V.A., Kornyushin, V.V., Varodi, E.I., Malega, O.M. (2008): Occurrence of Echinococcus multilocularis (Cestoda, Taeniidae) in red foxes (Vulpes vulpes) from Western Ukraine. Acta Parasitol., 53(1): 36 - 40. DOI: 10.2478/s11686-008-0008-9

Kinkar, L., Laurimäe, T., Simsek, S., Balkaya, I., Casulli, A., Manfredi, M.T., Manfredi, M.T., Ponce-Gordo, F., Varcasia, A., Lavikainen, A., González, L.M., Rehbein, S. van der Giessen, J., Sprong, H., SaArma, U. (2016): High-resolution phylogeography of zoonotic tapeworm Echinococcus granulosus sensu stricto genotype $\mathrm{G} 1$ with an emphasis on its distribution in Turkey, Italy and Spain. Parasitology, 143(13): 1790 -1801. DOI: 10.1017/S0031182016001530

Kinkar, L., Laurimäe, T., Sharbatkhori, M., Mirhendi, H., Kia, E.B., Ponce-Gordo, F., Andresiuk, V., Simsek, S., LaVIKaInen, A., IrShadullah, M., Umhang, G., Oudni-M'rad, M., Acosta-Jamett, G., Rehbein, S., SAARMA, U. (2017): New mitogenome and nuclear evidence on the phylogeny and taxonomy of the highly zoonotic tapeworm Echinococcus granulosus sensu stricto. Infect. Genet. Evol., 52: 52 - 58. DOI: 10.1016/j.meegid.2017.04.023

Knapp, J., Bart, J.M., Giraudoux, P., Glowatzki, M.L., Breyer, I., Raoul, F., Deplazes, P., Duscher, G., Martínek, K., Dubinský, P., Guislain, M.H., Cliquet, F., Romig, T., Malczewski, A., Gottstein, B., PiArroux, R. (2009): Genetic Diversity of the Cestode Echinococcus multilocularis in Red Foxes at a Continental Scale in Europe. PLoS Negl. Trop. Dis., 3(6): e452. DOI: 10.1371/journal.pntd.0000452 Kumar, S., Stecher, G., TAmuRA, K. (2016): MEGA7: Molecular evo- 
lutionary genetics analysis version 7.0 for bigger datasets. Mol. Biol. Evol., 33(7): 1870 - 1874. DOI: 10.1093/molbev/msw054

Mackenstedt, U., Jenkins, D., Romig, T. (2015): The role of wildlife in the transmission of parasitic zoonoses in peri-urban and urban areas. Int. J. Parasitol. Parasites Wildl., 4(1): 71 - 79. DOI: 10.1016/j.jppaw.2015.01.006

Maillard, S., Gottstein, B., HaAg, K.L., Ma, S., Colovic, I., BenChikh-Elfegoun, M.C., Knapp, J., Piarroux, R. (2009): The EmsB tandemly repeated multilocus microsatellite: a new tool to investigate genetic diversity of Echinococcus granulosus sensu lato. J. Clin. Microbiol. 47(11): 3608 - 3616. DOI: 10.1128/JCM.00938-09 Marcinkuté, A, Šarkūnas, M., Moks, E., Saarma, U., Jokelainen, P., Bagrade, G., Laivacumag, S., Strupash, K., Sokolovash V., Deplazes, P. (2015): Echinococcus infections in the Baltic region. Vet. Parasitol., 213(3 - 4): 121 - 131. DOI: 10.1016/j.vetpar.2015.07.032

Marinova, I., Spiliotis, M., Wang, J., Muhtarov, M., Chaligiannis, I., Sotiraki, S., Rainova, I., Gottstein, B., Boubaker, G. (2017): Molecular characterization of Echinococcus granulosus isolates from Bulgarian human cystic echinococcosis patients. Parasitol. Res., 116(3): 1043 - 1054. DOI: 10.1007/s00436-017-5386-1

Mitrea, I.L., Ionita, M., Costin, I.I., Ciopasiu, R., Constantinescu, C., TUDOR, V. (2010): Prevalence and morphological characterisation of Echinococcus granulosus larvae in some livestock from the South areas of Romania. Sci. Works C Ser. Vet. Med., 56(2): 114 - 123

Mitrea, I.L., Ionita, M., Wassermann, M., Solcan, G., Romig, T. (2012): Cystic echinococcosis in Romania: an epidemiological survey of livestock demonstrates the persistence of hyperendemicity. Foodborne Pathog. Dis., 9(11): 980 - 985. DOI: 10.1089/ fpd.2012.1237

Mitrea, I.L., Ionita, M., Costin, I.I., Predol, G., Avram, E., Rinaldi, L., Maurelli, MP, Cringoli, G, Genchi, C. (2014): Occurrence and genetic characterization of Echinococcus granulosus in naturally infected adult sheep and cattle in Romania. Vet. Parasitol., 206(3 - 4): 159 - 166. DOI: 10.1016/j.vetpar.2014.10.028

Moldovan, R., Neghina, A.M., Calma, C.L, Marincu, I., Neghina, R. (2012): Human cystic echinococcosis in two south-western and central-western Romanian counties: a 7-year epidemiological and clinical overview. Acta Trop. 121(1): 26 - 29. DOI: 10.1016/j.actatropica.2011.10.003

Nakao, M., Xiao, N., Окамoto, M., Yanagida, T., Sako, Y., Ito, A. (2009): Geographic pattern of genetic variation in the fox tapeworm Echinococcus multilocularis. Parasitol. Int., 58(4): 384 389. DOI: 10.1016/j.parint.2009.07.010

Neghina, R, Neghina, A.M., Marincu, I., IAcobiciu, I. (2010): Epidemiology and Epizootology of Cystic Echinococcosis in Romania 1862 - 2007. Foodborne Pathog. Dis., 7(6): 613 - 618. DOI: 10.1089/ fpd.2009.0489

Oksanen, A., Siles-lucas, M., Karamon, J., Possenti, A., Conraths, F.J., Romig, T., Wysocki, P., Mannocci, A., Mipatrinı, D., La Torre, G., Boufana, B., Casulli, A. (2016): The geographical distribution and prevalence of Echinococcus multilocularis in animals in the European Union and adjacent countries: a systematic review and meta-analysis. Parasit. Vectors. 9(1): 519. DOI: 10.1186/s13071016-1746-4

Panaltescu, D., Pop, M. (1999): Alveococoza la om. [Alveococcosis in man]. Rev. Rom. Parazitol., 9(2): 55 (In Romanian)

Piccoli, L., Bazzocchi, C., Brunetti, E., Mihallescu, P., Bandi, C., Mastalier, B., Cordos, I., Beuran, M., Popa, L.G., Meroni, V., GenCO, F., CRETU, C. (2013): Molecular characterization of Echinococcus granulosus in south-eastern Romania: evidence of G1-G3 and G6-G10 complexes in humans. Clin. Microbiol. Infect., 19(6): 578 - 582. DOI: 10.1111/j.1469-0691.2012.03993.x

Romig, T., EBI, D., Wassermann, M. (2015): Taxonomy and molecular epidemiology of Echinococcus granulosus sensu lato. Vet. Parasitol., 213(3 - 4): 76 - 84. DOI: 10.1016/j.vetpar.2015.07.035 Said-Ali, Z., Grenouillet, F., Knapp, J., Bresson-Hadni, S., Vuitton, D.A., Raoul, F., Richou, C., Millon, L., Giraudoux, P., Francechino NETWORK (2013): Detecting nested clusters of human alveolar echinococcosis. Parasitology, 140(13): 1693 - 1700. DOI: 10.1017/ S0031182013001352

SAvLovschI, C. (2000): Un caz de hidatidozã splenicã alveolarã. [A case of splenic alveolar hydatidosis]. Rev. Rom Parasitol. 10: 16 - 17 (In Romanian)

Seres, E., Avram, E., Cozma, V. (2006): Detection of Echinococcus coproantigens by enzyme-linked immunosorbent assay in dogs from the Northwest of Romania. Bull. USAMV-CN, 63, 395 - 398

Seres, E. Avram, E. Cozma, V. (2010): Coproantigen prevalence of Echinococcus spp. in rural dogs from Northwestern Romania. Sci. Parasitol., 11(3), 165 - 169

Schneider, R., Gollackner, B., Schindl, M., Tucek, G., Auer, H. (2010): Echinococcus canadensis $G 7$ (Pig Strain): An Underestimated Cause of Cystic Echinococcosis in Austria. Am. J. Trop. Med. Hyg., 82(5): 871 - 874. DOI: 10.4269/ajtmh.2010.09-0639 Schweiger, A., Ammann, R.W., Candinas, D., Clavien, P.A., Eckert, J., Gottstein, B., Halkic, N., Muellhaupt, B., Prinz, B.M., Reichen, J., Tarr, P.E., Torgerson, P.R, Deplazes, P. (2007): Human alveolar echinococcosis after fox population increase, Switzerland. Emerg. Infect. Dis., 13(6): 878 - 882. DOI: 10.3201/eid1306.061074

SIKÓ, B.S. (1992): [Some morphological aspects on alveolar hydatidosis in animals]. Rom. Vet. Rev., 2: 151 - 155 (In Romanian) SIKó B.S (1993): [Morphological aspects concerning alveolar hydatidosis in wild rodents]. Rom. Vet. Rev. 3: 214 - 216 (In Romanian)

Sikó, B.S., Bokor, E., Fekés, E., Nemes, I., Mural, E., Gubányı, A. (1995): Occurrence and epidemiology of Echinococcus granulosus and E. multilocularis in the Covasna county, East Carpathian Mountains, Romania. Parasitol. Hung. 28: 43 - 56

Sikó, B.S., Stefanolu, V., Iacobiciu, I., Corolu, Z., Cozma, V., AnDRONIE, V., SZIGETHY, I. (2002): Echinococcosis-Hydatidosis in Romania. First Volume - Epidemiological Report. ECHINO-NEWS Association - South-East Europe and Balkan Inform Center on Echinococcosis - Hydatidosis \& National Institute of Research-Development for Microbiology and Immunology Cantacuzino, Sf. Gheorghe-Bucharest 
Sikó, S.B., Deplazes, P., Ceica, C., Tivadar, C. S., Bogolin, I., Popescu, S., Cozma, V. (2011): Echinococcus multilocularis in south-eastern Europe (Romania). Parasitol. Res., 108(5): 1093 1097. DOI: 10.1007/s00436-010-2150-1

Šnábel, V., Miterpáková, M., D’Amelio, S., Busı, M., Bartková, D., TurČeková, L', Maddox-Hyttel, C., Skuce, P., Dubinský, P. (2006): Genetic structuring and differention of Echinococcus multilocularis in Slovakia assessed by sequencing and isoenzyme studies. Helminthologia, 43(4): 196 - 202. DOI:10.2478/s11687-006-0037-6

Šnábel, V., Altintas, N., D’Amelio, S., Nakao, M., Romig, T., Yolasigmaz, A., Gunes, K., Turk, M., Busi, M., Hüttner, M., Ševcová, D., Ito, A. Altintas, N. DubinskÝ, P. (2009): Cystic echinococcosis in Turkey: genetic variability and first record of the pig strain (G7) in the country. Parasitol. Res., 105(1): 145 - 154. DOI: 10.1007/ s00436-009-1376-2

Šnábel, V., D’Amelio, S., Nakao, M., Romig, T., Schroer, S., Boucher, J.M., MiterpákovÁ, M., DubinskÝ, P. (2010): Genetic variation of Echinococcus multilocularis from Europe assessed by DNA sequencing. In Program and Abstracts of the Workshop „Epidemiology of Alveolar Echinococosis in Europe. Monitoring and Control Perspectives, Recent Developments and New Trends ", December 8 - 9, 2010, Nancy, France, p. 62

Šnábel, V., Kuzmina, T., Cavallero, S., D’Amelio, S., Georgescu, S.O., SzénÁsi, Z., Cielecka, D., Salamatin, R., Yemets, A., Kucsera, I. (2016): A molecular survey of Echinococcus granulosus sensu lato in central-eastern Europe. In Open Life Sci., 11(1): 524 - 532. DOI: 10.1515/biol-2016-0066
Szilágyiová, M., Laca, L'., Antolová, D., Nováková, E., Rosolanka, R., ReITEROVÁ, K., ŠImeKovÁ K. (2015): Importance of complex diagnostic approach in differential diagnosis of alveolar echinococcosis. Helminthologia, 52(4): 298 - 302. DOI: 10.1515/helmin-2015-0047 Taberlet, P., Fumagalli, L., Wust-Saucy, A.G., Cosson, J.F. (1998): Comparative phylogeography and postglacial colonization routes in Europe. Mol. Ecol., 7(4): 453 - 464.

Todorov, T., Boeva, V. (1999): Human echinococcosis in Bulgaria: a comparative epidemiological analysis. Bull. WHO, 77(2): 110 - 118 Torgerson, P.R., Keller, K., Magnotta, M., Ragland N. (2010): The Global Burden of Alveolar Echinococcosis. PLoS Negl. Trop. Dis., 4(6): e722. DOI: 10.1371/journal.pntd.0000722

Torgerson, P.R., MacPherson, C.N.L. (2011): The socioeconomic burden of parasitic zoonoses: global trends. Vet. Parasitol., 182(1): 79 - 95. DOI: 10.1016/j.vetpar.2011.07.017

TurČeková, L'., ŠnÁBel, V., Dudiñák, V., GašPAR, V., DubinskÝ, P. (2009): Prevalence of cystic echinococcosis in pigs from Slovakia, with evaluation of size, fertility and number of hydatid cysts. Helminthologia, 46(3): 151 - 158. DOI: 10.2478/s11687-009-0029-4 Xiao, N., QIu, J., Nakao, M., Nakaya, K., Yamasaki, H., Sako, Y., Mamuti, W., Schantz, P.M., Craig, P.S., Ito, A. (2003): Short report: Identification of Echinococcus species from a yak in the Qinghai-Tibet plateau region of China. Am. J. Trop. Med. Hyg., 69(4): $445-446$

Xiao, N., Qiu, J., Nakao, M., Tiaoying, L., Yang, W., Chen, X., Schantz, P.M., Craig, P.S., Ito, A. (2005): Echinococcus shiquicus n. sp., a taeniid cestode from Tibetan fox and plateau pika in China. Int. J. Parasitol., 35(6): 693 - 701. DOI: 10.1016/j.ijpara.2005.01.003 